Jpn. J. Human Genet. 31, 353-355, 1986

\title{
GENE FREQUENCIES OF $S$-FORMYLGLUTATHIONE HYDROLASE ISOZYME IN A JAPANESE POPULATION
}

\author{
Katsunori Akiyama and Kazue ABe \\ Department of Legal Medicine, Tokyo Women's Medical College, \\ Kawada-cho, Shinjuku-ku, Tokyo 162, Japan
}

\begin{abstract}
Summary Genetic polymorphism of $S$-formylglutathione hydrolase (FGH) was investigated in a total of 581 red blood cell samples from unrelated Japanese using the starch gel electrophoresis and the enzymeactivity staining procedure. Three common phenotypes, FGH 1, FGH 2-1, and FGH 2, determined by two alleles, $F G H^{*} I$ and $F G H^{*}$ 2, were observed. The gene frequencies of $F G H^{*} 1$ and $F G H^{*} 2$ in Japanese were estimated to be 0.67 and 0.33 , respectively. The gene frequencies were different from those for Japanese reported by Board and Coggan (1986).
\end{abstract}

\section{INTRODUCTION}

$S$-Formylglutathione hydrolase [EC 3.1.2.12; FGH], which catalyze the hydrolysis of thiol esters of glutathione, has been found in human tissues including red blood cells (Uotila, 1973). Uotila (1984) reported that human red blood cell FGH exhibits the genetic polymorphism with three common phenotypes determined by two autosomal codominant alleles, $F G H^{*} l$ and $F G H^{*}$, using a polyacrylamide gel isoelectric focusing followed by the enzyme-activity staining method: the gene frequencies of $F G H^{*} 1$ and $F G H^{*} 2$ in a Finnish population were estimated as 0.99 and 0.01 , respectively. Recently, Board and Coggan (1986) analyzed the FGH polymorphisms in several racial groups and reported that the gene frequencies of $F G H^{*} 1$ and $F G H^{*} 2$ in Japanese living in Australia were estimated as 0.49 and 0.51 , respectively,

In this paper, we describes the data on the distribution of the phenotypes and the gene frequencies of FGH in 581 unrelated Japanese.

\section{MATERIALS AND METHODS}

Samples. Fresh blood samples in EDTA solution were collected from 581 unrelated blood donors in Tokyo. Hemolysates were made by freezing and thawing from washed packed red blood cells.

Received June 17, 1986; Accepted July 19, 1986 
Electrophoresis. The phenotypes of FGH were determined by starch gel electrophoresis, essentially the same method as described by Board and Coggan (1986). Electrophoresis was carried out for $16-18 \mathrm{hr}$ using a continuous buffer system $(0.1 \mathrm{M}$ Tris, $0.1 \mathrm{M}$ maleic acid, $0.01 \mathrm{M}$ EDTA, $0.01 \mathrm{M} \mathrm{MgSO}_{4}$; the $\mathrm{pH}$ was adjusted to 7.4 with $1 \mathrm{~m} \mathrm{NaOH})$. The gel buffer was a $1: 10$ dilution of the electrode buffer $(18 \%$ hydrolyzed starch). Horizontal electrophoresis was performed by $6 \mathrm{~V} / \mathrm{cm}$ at $4^{\circ} \mathrm{C}$.

Staining method. The enzyme-activity staining was carried out according to the method of Uotila (1984). The staining mixture consisted of $10 \mathrm{mg} S$-acetylglutathione, $10 \mathrm{mg} \mathrm{MTT,} 2 \mathrm{mg}$ 2,6-dichlorophenolindophenol, $15 \mathrm{ml}$ of $0.1 \mathrm{M}$ Tris- $\mathrm{HCl}$ buffer ( $\mathrm{pH} 8.0$ ) and $20 \mathrm{ml}$ of agar solution (approx. $2 \%$ ) at $55^{\circ} \mathrm{C}$. These were mixed and quickly poured over the sliced starch gel. The gel was incubated at $37^{\circ} \mathrm{C}$ for $30 \mathrm{~min}$. Then the appearance of the dark blue color was observed and the phenotypes were determined.

\section{RESULTS AND DISCUSSION}

Figure 1 shows the three common phenotypes of FGH 1, FGH 2-1 and FGH 2. Each of the two homozygous phenotypes exhibits a single spot with FGH activity of a different anodal mobility from each other, and the heterozygous phenotype is represented by the dimeric pattern. This seems to coincide with the finding of Board and Coggan (1986). In our samples, there were no variant types deviating from the three common phenotypes.

Table 1 shows the inheritance of FGH phenotypes. Family studies including 41 families and 50 offsprings were done to test the genetic hypothesis. The pattern of inheritance is consistent with codominant inheritance of two alleles at a single autosomal locus. Any unexpected type was not observed in the children.

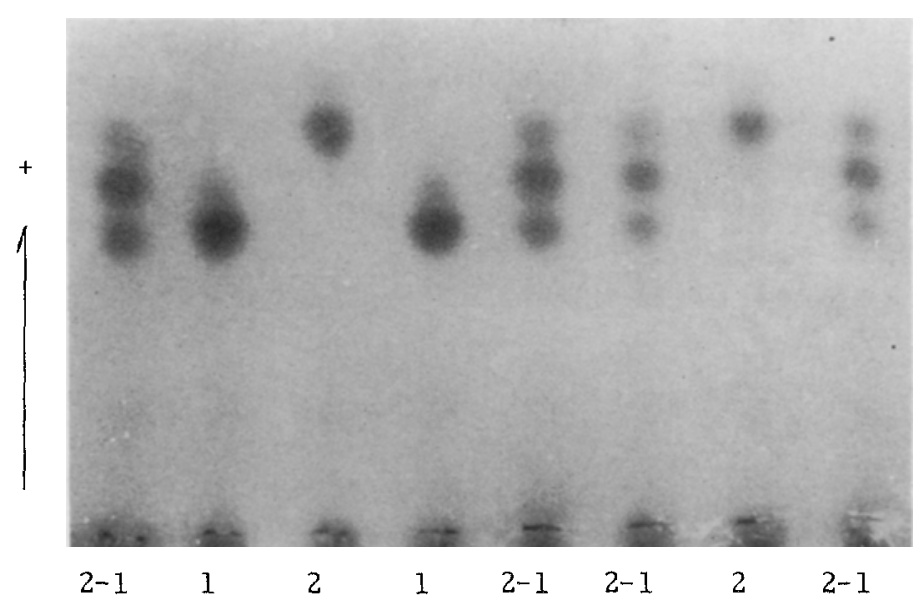

Fig. 1. Zymogram of three common phenotypes of FGH electrophoretic patterns. 
Table 1. Phenotypes of FGH in families.

\begin{tabular}{ccccc} 
& No. families & \multicolumn{3}{c}{ Offspring types } \\
\cline { 3 - 5 } Parental types & 8 & 1 & $2-1$ & 2 \\
\hline $1 \times 1$ & 2 & 10 & 0 & 0 \\
$2 \times 2$ & 7 & 0 & 0 & 2 \\
$1 \times 2$ & 13 & 0 & 9 & 0 \\
$1 \times 2-1$ & 6 & 9 & 7 & 0 \\
$2 \times 2-1$ & 5 & 0 & 3 & 5 \\
$2-1 \times 2-1$ & & 2 & 2 & 1 \\
\hline
\end{tabular}

Table 2. Distribution of FGH phenotypes among 581 unrelated Japanese.

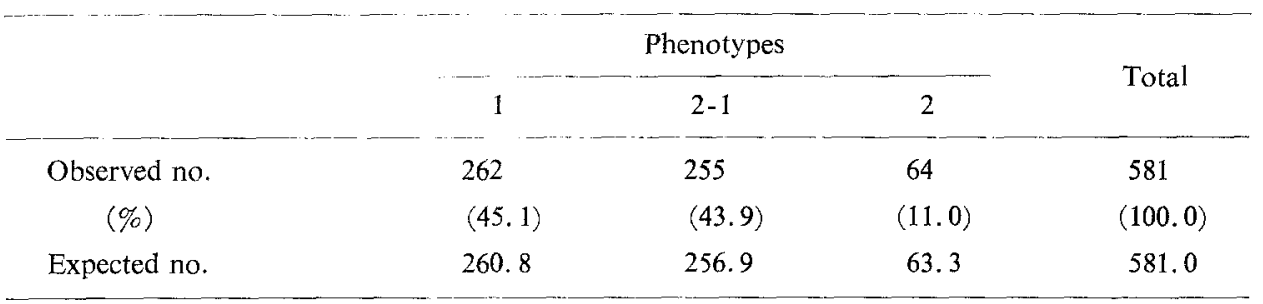

Gene frequencies: $F G H^{*} 1=0.67, F G H^{*} 2=0.33 . \quad \chi^{2}=0.028$, d.f. $=1,0.90<\mathrm{p}<0.75$.

The phenotypic distribution and the gene frequencies in a total of 581 Japanese blood samples are given in Table 2. The gene frequencies of $F G H^{*} l$ and $F G H^{* 2}$ were estimated to be 0.67 and 0.33 , respectively. On the basis of the Hardy-Weinberg equilibrium, there was a good agreement between the observed and expected numbers $\left(\chi^{2}=0.028\right.$, d.f. $\left.=1,0.90>p>0.75\right)$. The frequencies of the two alleles observed in this study were different from those for Japanese living in Australia $\left(F G H^{*} 1=0.49, F G H^{*} 2=0.51\right)$ reported by Board and Coggan (1986). The frequency of $F G H^{*} I(0.67)$ in Japanese is much lower than that in Finn (0.99), Australian (0.89), South African (0.99) and Indian (0.80), and simmilar to that in Western Samoan (0.64) and Chinese (0.71), reported previously (Uotila, 1984; Board and Coggan, 1986).

Note Added in Proof: After this paper had been submitted, we observed that the phenotypes of FGH were identical with those of esterase D in each sample used in this study. It is considered that the esterase D hydrolyze the glutathione thiol ester group of $S$-formylglutathione. FGH reported by Uotila (1984) and Board and Coggan (1986) is very likely to be esterase D.

Acknowledgment We are grateful to Miss. Junko Ochi and Mr. Yoshihiro Obara for their technical assistance. 


\section{REFERENCES}

Board, P.G. and Coggan, M. 1986. Genetic heterogeneity of S-formylglutathione hydrolase. Ann. Hum. Genet. 50: 35-39.

Uotila, L. 1973. Preparation and assay of glutathione thiol esters. Survey of human liver glutathione thiol esterases. Biochemistry 12: 3938-3947.

Uotila, L. 1984. Polymorphism of red cell $S$-formylglutathione hydrolase in a Finnish population. Hum. Hered. 34: 273-277. 